\title{
Experiências de formação inicial de professores de inglês em contexto extensionista: discutindo a multimodalidade e os materiais didáticos
}

\author{
Ana Karina de Oliveira Nascimento ${ }^{1}$
}

Maria Amália Vargas Façanha²

\section{Resumo}

Entendendo o processo de formação docente como plural, este artigo investiga a formação inicial de professores de inglês que se deu no projeto de extensão Formação de Professores de Inglês como Lingua Adicional, em especial através do módulo English Language Materials, segundo as teorias dos novos letramentos (MENEZES DE SOUZA, 2011) e multimodalidade (KRESS, 2003). Trata-se de análise exploratória de cunho etnográfico, delineada como um estudo de caso etnográfico, a qual objetiva problematizar como os participantes, dois professores em formação, voluntários na extensão, após suas experiências vividas ao longo do projeto, entendem a multimodalidade e o papel dos materiais didáticos, principalmente do livro didático, no ensino de inglês. Os resultados principais, os quais são discutidos no texto por meio de uma narrativa descritivo-teórica, apontam para interessantes realinhamentos na formação docente desses participantes, ainda que seja possivel evidenciar alguns posicionamentos contraditórios. Concluimos apontando que as participações dos professores em formação inicial na ação extensionista promoveram um (re)pensar das práticas docentes, principalmente no que concerne às questões de multimodalidade e do livro didático de inglês.

Palavras-chave: Formação inicial. Professores de inglês. Extensão. Multimodalidade. Material didático

\footnotetext{
${ }^{1}$ Docente na Universidade Federal de Sergipe e doutoranda em Estudos Linguísticos e Literários em Inglês na Universidade de São Paulo.

2 Docente na Universidade Federal de Sergipe e doutoranda em Educação na Universidade Federal de Sergipe.
} 


\section{Introdução}

Nossas experiências de formação, foco nesse artigo, começam em meados de 2016, quando resolvemos, um grupo composto de sete (7) docentes de uma mesma instituição e um de uma instituição parceira, concorrer a um edital de bolsas de iniciação à extensão na universidade pública onde a maioria leciona, doravante denominada Universidade Pública Brasileira (UPB $)^{3}$, no nordeste do Brasil. Junto a esse grupo de docentes, foram agregados quatro orientandos ou ex-orientandos de mestrado ou doutorado ligados aos professores participantes, além de cinco estudantes de graduação, sendo apenas um deles bolsista de extensão; os demais, voluntários no projeto intitulado Formação continuada de professores de inglês como língua adicionalt, o qual teve como período de realização de 16 de janeiro a 15 de dezembro de 2017. O projeto faz parte das ações do grupo de pesquisa da mesma instituição intitulado Letramentos em Inglês: lingua, literatura e cultura, ligado ao Projeto Nacional de Letramentos: linguagem, cultura, educação e tecnologia, com sede na Universidade de São Paulo.

O projeto local teve como um dos seus desdobramentos a oferta de cursos de formação continuada a professores de inglês de escolas públicas do estado onde se localiza a universidade. Para tanto, foram criados quatro módulos, de 40 horas de duração cada, objetivando o desenvolvimento profissional de professores de inglês da rede pública, com vistas ao aperfeiçoamento de suas práticas de sala de aula, bem como de suas habilidades na língua inglesa. Para a realização de cada um dos módulos, 40 vagas foram oferecidas. Para fins de construção desse texto, e levando em conta os limites impostos por um artigo, nosso foco estará no módulo 3 intitulado English Language Materials, e, mais especificamente no trabalho desenvolvido ao longo dessa etapa, levando em conta as participações e percepções sobre o trabalho desenvolvido de dois dos graduandos participantes dessa etapa, Krisler e Jane ${ }^{5}$, orientados pelas duas autoras desse texto.

Para fins de organização desse artigo, optamos por escrevê-lo como uma narrativa descritiva e teórica. Dessa forma, ao tempo em que narramos nossas experiências e trazemos as falas dos participantes, realizamos nossa análise, lançando mão das teorias que

\footnotetext{
${ }^{3}$ Como garantia de anonimato, pseudônimos foram adotados ao longo desse texto quando nos referimos à instituição onde a ação de extensão foi realizada, bem como aos participantes da presente pesquisa.

4 A nossa opção pelo uso do termo língua adicional e não língua estrangeira para se referir ao inglês no projeto justifica-se pelo nosso entendimento de que é possível ultrapassar a discussão língua minha e língua do outro, falante nativo e estrangeiro e adotar uma posição menos conflitante de convivência de diferentes línguas que se somam. Para mais informações sobre o conceito de língua adicional, ver: Leffa e Irala (2014); Schlatter e Garcez (2012).

5 Todos os sujeitos envolvidos assinaram o Termo de Consentimento Livre e Esclarecido.
} 
nos embasam, bem como do que os dados coletados nos permitem dizer. Trata-se de uma análise exploratória de cunho etnográfico, delineada como um estudo de caso etnográfico (ANDRÉ, 1995) realizada no período de 26 de agosto a 22 de novembro de 2017. O módulo compreendeu seis encontros presenciais nos quais os dois graduandos participantes dessa pesquisa e as duas orientadoras estiveram sempre presentes, ocorridos no período de 26 de agosto a 7 de outubro, sempre aos sábados, das 9 às 13 horas, no prédio da Secretaria de Estado da Educação, em virtude de convênio firmado entre os organizadores do projeto e a referida Secretaria. Embora tendo os encontros sido finalizados em 07 de outubro, as atividades tiveram continuidade online de forma que, até 7 de novembro, os professores participantes pudessem enviar seu trabalho final: a elaboração de um artefato didático (material a partir do livro didático, plano de aula envolvendo materiais, preparação de material e sequência didática, etc.) para uso em sua sala de aula. Até essa data limite os docentes participantes do curso puderam enviar às duas autoras desse texto suas produções, as quais também foram compartilhadas via Google Drive com todos os participantes do módulo.

A conclusão total do módulo, portanto, deu-se a posteriori. Na verdade, o módulo foi finalizado apenas em 22 de novembro, quando todos os professores puderam receber feedback individuais das atividades propostas e o questionário aplicado junto aos dois graduandos participantes pôde ser finalizado. Assim, os dados discutidos ao longo desse texto advêm de nossas observações, dos nossos diários de campo, bem como de um questionário aplicado a esses dois graduandos, instrumento principal utilizado ao longo da análise presente nesse artigo.

Nosso objetivo central é, por meio desse texto, problematizar os diversos entendimentos desses professores em formação inicial inseridos no contexto de formação continuada, acerca da multimodalidade no ensino de língua inglesa, bem como do papel dos materiais didáticos utilizados no ensino de inglês, especialmente do livro didático. Isso levando em conta as experiências vivenciadas ao longo do módulo English Language Materials.

Entendemos que todas as leituras são parciais, e, portanto, nunca definitivas. Ao contrário, sempre sujeitas a releituras. Por isso, a análise aqui compartilhada é parte de uma reflexão contextual recheada das mais diversas nuances. Além disso, entendemos a dinamicidade e continuidade inerente ao processo de formação docente. Assim, embora 
tenhamos divido esse texto em partes, para fins didáticos, temos a consciência de que há um entrelaçar-se constante de falas, interpretações, ações, construções e desconstruções, e desde já deixamos isso claro ao leitor, apesar do nosso esforço de tentar congelar a dinamicidade do processo ao longo do presente texto, especialmente quando nosso foco recai na formação inicial de professores, portanto, em graduandos, mas que se dá permeada por um processo de formação continuada; que aliás, confunde-se com o nosso próprio processo de formação enquanto professores formadores.

\section{Quem sou eu nesse projeto de extensão? Os professores em formação inicial e suas impressões...}

Na organização do módulo 3, English Language Materials, éramos quatro pessoas atuando de forma mais direta, ainda que contando com o suporte, feedback e comentários dos demais membros da equipe do projeto. Duas de nós, professoras formadoras da UPB, com mais de 20 anos de prática de ensino de inglês e mais de 10 anos de atuação como formadoras de professores. Ainda, contamos com a participação atenta de uma doutoranda da UPB, servidora da universidade com formação em língua inglesa que também se interessou por fazer parte do grupo, estando presente na maior parte do processo. Junto a nós, dois graduandos mostrando-se muito atentos e participativos ao longo de todo o módulo.

Krisler, estudante do $8^{\circ}$ período do curso de Letras Inglês da UPB, com experiência de aprendizado de inglês, além da escola regular (instituição privada), por meio de curso de idiomas. Jane, estudante do $4^{\circ}$ período do curso de Letras Português/Inglês na mesma instituição, com experiência de aprendizado de inglês em escola pública do $6^{\circ}$ ao $3^{\circ}$ ano da educação básica. Segundo ela, “aprendi inglês estudando sozinha, em casa. Mas, tive aulas de inglês em escolas públicas” (Fonte: questionário respondido por Jane, p. 1).

No ensino superior, seus caminhos se cruzam em algumas vielas. Primeiramente, por ambos fazerem parte do Programa Institucional de Bolsas de Iniciação à Docência (Pibid). O primeiro, desde 2015, e a segunda, desde 2016. Segundo, por suas participações, durante a graduação, em ações, além do próprio curso de graduação, que pudessem proporcionar o aprendizado da língua inglesa, tais como aquelas oferecidas pelo Programa Inglês sem Fronteiras (IsF) da UPB, seja por meio de aulas de língua inglesa a alunos da 
instituição, seja por meio das ações organizadas pelos English Teaching Assistants (ETA) que atuam junto aos cursos de graduação em Letras Inglês da instituição, tais como aulas de conversação. Por fim, seus caminhos se cruzam mais uma vez no momento em que ambos se voluntariam para participar do Projeto Formação continuada de professores de inglês como língua adicional, por meio do qual atuam juntos no módulo 3, sendo protagonistas das ações.

Em uma das primeiras reuniões realizadas, envolvendo os quatro participantes dessa jornada aqui sendo narrada, Krisler e Jane trouxeram como um dos primeiros questionamentos o que eles deveriam fazer. Seria passar lista de presença? Organizar material? Digitalizar ou copiar textos? Às suas várias indagações fizemos questão de afirmar que um dos papeis mais importantes a ser por eles desempenhado seria, especialmente, participar ativamente de todas as ações do módulo, o que incluiria estar presente em todos os encontros de forma participativa e não apenas como coadjuvantes, de maneira que aqueles momentos também representassem oportunidades de formação para eles. Assim, compartilhamos os objetivos traçados para o módulo, dos quais destacamos: problematizar as possibilidades de usos de materiais didáticos de língua inglesa, com foco no livro didático (LD) do Programa Nacional do Livro Didático (PNLD), especialmente tratando do reconhecimento da imagem e outros recursos multimodais como textos, segundo uma perspectiva dos novos letramentos.

Como parte do planejamento das atividades do módulo 3, em virtude das nossas escolhas teórico-práticas, compartilhamos com os nossos graduandos participantes e demais membros do projeto, antes do início do módulo, alguns textos que havíamos pensado em trabalhar com os participantes. Dessa forma, todos poderiam ajudar na construção do módulo, mesmo sem ainda sabermos quais seriam os materiais e livros didáticos trazidos pelos professores da rede pública participantes, questão que seria abordada apenas após o início do módulo. Diante disso, alguns dos textos selecionados foram mantidos, outros acrescentados a um programa inicialmente traçado para o trabalho ao longo do módulo ${ }^{6}$. Assim, Krisler e Jane tiveram acesso aos materiais e à nossa discussão sobre possíveis inclusões e exclusões de materiais antes dos professores das escolas.

\footnotetext{
${ }^{6}$ Cabe esclarecer que as alterações de textos em virtude das negociações ocorreram por meio das sugestões dos demais idealizadores do projeto, professores da UPB, levando em conta, principalmente, as experiências vividas nos módulos anteriores. Assim, deixamos claro que não houve sugestão de textos por parte dos graduandos, ainda que tenhamos proporcionado espaço para que eles sugerissem.
} 
Por conta da decisão do grupo de enfatizar, no módulo, o livro didático, resolvemos, no primeiro encontro do módulo, ocorrido em 26 de agosto de 2017, pedir que os professores participantes se apresentassem, mencionando as escolas onde atuavam, a localização das mesmas, bem como os materiais didáticos utilizados; no caso de livros didáticos, quais os adotados, se eram recebidos (ou não) e se eram por eles utilizados (ou não). Obtivemos naquele momento respostas variadas, mas que convergiam para uma maioria utilizando o livro didático que faz parte das coleções do PNLD. Diante desse fato, perguntamos aos graduandos Krisler e Jane sobre essa questão; em especial, gostaríamos de conhecer um pouco de suas experiências de uso de material didático, especialmente do livro didático, como discentes e docentes de inglês em formação, e, de forma mais específica como enxergavam a sua relação com multimodalidade. Ao refletirem sobre suas experiências, Krisler mencionou os usos feitos atualmente na graduação, ao afirmar que, como discente, ele o utiliza nas aulas de língua inglesa, o que é de fato uma prática na UPB. Jane, por sua vez, conectou suas experiências à educação básica, ao afirmar:

Nas escolas públicas em que estudei sempre houve o uso do livro didático de inglês. Normalmente tínhamos que traduzir textos e responder os exercícios. Mas meus professores não problematizavam o conteúdo do livro conosco e nem trabalhavam a gramática criticamente. Além disso, o CD que vem junto com o livro raramente era utilizado (Fonte: questionário respondido por Jane, p. 1, grifos nossos).

Essa percepção relativa à forma como o ensino do idioma aconteceu antes da sua inserção na universidade, com ênfase em elementos linguísticos, através da tradução de textos e do ensino tradicional da gramática, com destaque para a ausência de momentos de análise crítica, pode ter sido provocada pelo contato com os estudos dos novos letramentos, que entendem a língua como prática social. Teorias essas que embasaram as atividades do módulo, bem como as experiências de sala de aula vivenciadas pelos discentes em suas participações no Pibid. Questões trabalhadas durante o módulo, por exemplo, trataram da natureza sociocultural envolvida nas práticas de novos letramentos (GEE, 2008), destacando-se que:

Para os estudos sobre novos letramentos, o letramento é socialmente construído e abordagens pedagógicas do letramento compreendem e enfatizam a natureza social da aprendizagem e a importância das comunidades discursivas que se estabelecem nas salas de aula, encarando a aprendizagem como pequenas modificações na forma de participação dos aprendizes (MATTOS, 2015, p. 53). 
Mattos (2015) busca em Larson e Marsh (2005) explicação para essas pequenas modificações que ocorrem no aprendizado, como sendo o aumento das habilidades e expertise ao longo do tempo, as quais vão além da aprendizagem de elementos estruturais e mecânicos, como é o caso de metodologias mais tradicionais que enfatizam o ensino da gramática, por exemplo, sem problematizar os conteúdos. Esses autores declaram que "as pessoas aprendem por meio da participação em atividades culturalmente valorizadas" (LARSON; MARSH, 2005, p. 10 apud MATTOS, 2015, p. 53), como foi o caso das experiências vividas no módulo, as quais buscaram valorizar os contextos de ensino e aprendizagem da língua inglesa.

Um exemplo dessa valorização foi compartilhado por um dos professores participantes do módulo. Quando tratávamos da experiência com a imagem como texto, uma das professoras indicou o trabalho que realizou com um dos seus alunos na escola pública. Este, sendo considerado um aluno desinteressado e pouco participativo, teve suas atitudes modificadas quando a ele foi dada a chance de expressar sua arte na própria escola, por meio do entendimento de que o grafite que ele produzia era uma forma de linguagem, de expressão de pensamento. E isso se deu por meio da abertura proporcionada por uma das atividades presentes no livro didático de língua inglesa.

Tal exemplo conecta-se à ideia de que o que entendemos como novos letramentos difere do conceito primeiro de letramento, atrelado à alfabetização, inicialmente adotado no contexto brasileiro. Aqui ampliamos o conceito para entender letramentos como práticas diversas de construção de sentido que vão além do texto alfabético, englobando, no contexto aqui discutido, a multimodalidade. Assim, ampliamos o nosso entendimento para o de novos letramentos, considerando uma mudança paradigmática, da perspectiva psicolinguística para uma perspectiva sociocultural de entender os letramentos, bem como ontológica, relacionada às diferentes configurações de práticas sociais que surgem, impulsionadas, especialmente, pelas tecnologias digitais. Estamos tratando das mudanças nas formas como nos relacionamos, trabalhamos, estudamos, etc., ou seja, das novas práticas sociais que emergem e modificam letramentos passados. Dizemos isso levando em conta que:

o conceito antigo de alfabetização era ensinar a ler e escrever. Havia o pressuposto de que bastava ensinar o alfabeto que a pessoa saía escrevendo e lendo [...]. Então, na década de 70 surgiu o termo 'letramento', para se contrapor ao conceito de 'alfabetização'. Letramento era aprender como usar a escrita em determinados contextos 
diferentes. Escrever uma carta era diferente de escrever um conto, um currículo [...], eram formas diferentes de escrita que exigiam habilidades de leitura diferentes. Não é todo mundo que pode escrever esses vários textos de forma igual, não basta saber o alfabeto para saber ler contrato e compreender tudo na nossa língua materna. Assim surgiu o conceito de que a escrita e a leitura eram práticas sociais manifestadas de formas diferentes em comunidades diferentes e em contextos diferentes. (MENEZES DE SOUZA, 2011, p. 285-286).

Em se tratando de suas experiências com o livro didático como docentes de inglês em formação, os graduandos citaram como essa relação tem se estabelecido no Pibid: por meio da preparação e das práticas nas salas e aula da escola pública onde atuam como bolsistas atualmente. Jane complementou afirmando que a inserção do livro didático nas práticas do Pibid era algo novo, visto que não vinha sendo utilizado anteriormente. E acrescentou que a ideia do programa atualmente, segundo sua percepção, é “[...] desenvolver planos de aula que utilizem o livro, dando continuidade às aulas dos supervisores. Tudo isso baseado na teoria dos letramentos [...]" (Fonte: questionário respondido por Jane, p. 1). E continuou fazendo a ressalva de que, no Pibid, os graduandos são incentivados a fazer uso dos materiais didáticos de que a escola dispõe, considerando novas e variadas formas de utilizá-lo.

No que concerne à relação livros didáticos de inglês e multimodalidade, Krisler não respondeu a essa pergunta. Jane, por sua vez, afirmou que não tinha familiaridade com essa teoria até o seu ingresso na universidade, quando o tema foi primeiramente abordado por meio da disciplina Produção e Recepção de texto I ${ }^{7}$.

Após esse contato inicial com quem são os participantes das ações extensionistas de formação e suas experiências no que concerne às principais questões tratadas ao longo do módulo, damos continuidade analisando suas atuações no curso de extensão, bem como suas percepções sobre o quanto o módulo pode ter contribuído para suas formações docentes.

\section{Em ação! Eu também sou parte das ações extensionistas!}

Krisler e Jane foram motivados a vivenciar o módulo não apenas como nossos auxiliares, contribuindo com a logística do curso, mas também de forma que eles

\footnotetext{
${ }^{7}$ Essa disciplina, pertencente ao quadro de disciplinas do $1^{\circ}$ período do curso de Letras Português/Inglês da $\mathrm{UPB}$, tem como um dos seus principais objetivos trabalhar o conceito de texto e sua caracterização.
} 


\section{Experiências de formação inicial de professores de inglês em contexto extensionista: discutindo a multimodalidade e os materiais didáticos \\ Ana Karina de Oliveira Nascimentos, Maria Amália Vargas Façanba}

reconhecessem ser o curso mais um momento de formação, conforme dito anteriormente. Para tal, eles foram incentivados a mesclarem-se com o grupo de docentes já experientes, ouvindo-os, com eles dialogando, principalmente em razão da vivência deles com a escola pública, o que se deu conforme os encontros aconteciam.

Essa atitude fez com que Krisler e Jane pudessem se sentir parte integrante do grupo de professores, o que foi mencionado por Krisler quando ele destaca que, além do papel como ajudante e monitor, ele se reconheceu como colega dos outros participantes, ressaltando que "estivemos em uma posição em que tínhamos liberdade para questionar, aprender e compartilhar em todo o momento, mas obviamente aprendemos mais do que compartilhamos nessa rica experiência" (Fonte: questionário respondido por Krisler, p. 1).

Jane destacou a relação que foi construída entre ela e os docentes das escolas por meio de tarefas que ficaram sob sua responsabilidade, com nossa supervisão, tais como: comunicação via e-mail com os participantes, sempre enviando resumos dos encontros; comunicação nas redes sociais (criação de grupo no WhatsApp e colaboração no gerenciamento de grupo fechado no Facebook). Essas tarefas contribuíram para que ela desenvolvesse afinidade com os docentes participantes e conosco, as orientadoras. A forma como ela entendeu sua participação aponta para a compreensão de que aquela experiência foi vivida por ela como mais um momento de formação, conforme declarado abaixo:

Eu estava presente em todos os encontros presenciais, sempre fazendo anotações e participando das atividades. Aprendi muito com o módulo e, acredito que cresci muito como futura professora. Os assuntos discutidos no módulo despertaram minha atenção quanto aos textos e me fizeram (ainda fazem) refletir muita coisa, o que é muito importante porque eu não quero impor minhas crenças aos meus alunos, no futuro, quero desconstruir as verdades deles para reconstruir (Fonte: questionário respondido por Jane, p. 3, grifos nossos).

No planejamento do módulo, pensamos em atividades práticas de letramentos das quais os discentes participaram ativamente, aí incluídas as conversas embasadas nas leituras feitas ao longo dessa vivência. Tudo aconteceu contemplando duas temáticas, multimodalidade, com foco nas imagens, e, o livro didático de inglês. Trabalhamos com outros materiais didáticos, mas o foco central esteve nos livros didáticos das coleções do PNLD, por serem eles os materiais mais presentes nos contextos de ensino dos participantes, conforme pudemos verificar no nosso primeiro encontro com o grupo, o que está em consonância com a afirmação de Santos (2011) de que o LD ainda é o instrumento didático mais presente nas salas de aula brasileiras. 
Os olhares lançados sobre a produção de significados que podem surgir da interação entre o LD e seus usuários (docentes e discentes) levaram em conta a compreensão de que "os significados de um livro estão sempre em fluxo e constantemente negociados, rejeitados, confirmados, elaborados, legitimados, reforçados - em suma, reconstruídos pelos indivíduos [...] em interação” (SANTOS, 2011, p. 64). Nessa perspectiva, destacamos a seguinte afirmação de Krisler:

O módulo representou um marco em minha visão da relação existente entre o professor, os alunos e o material didático. Até então eu acreditava que o livro didático tinha pouco a oferecer para o professor e o aluno, mas durante as reuniões vimos a riqueza de informações que uma simples foto pode trazer. Mudou minha perspectiva do material didático quando eu percebi que a ferramenta sozinha não vai fazer uma aula, mas o uso correto dessa ferramenta pode fazer com que a aula ocorra (Fonte: questionário respondido por Krisler, p. 1).

A visão apresentada por Krisler sobre o livro didático demonstra mudanças ocorridas no seu entendimento sobre o papel desse material, em especial, focando na interação necessária entre livro didático, professor e estudantes, para além do seu entendimento anterior de livro como algo estático com pouco a oferecer ao professor e ao aluno, além do que parece estar claramente explicitado no material. Essa mudança de perspectiva, entretanto, o levou a tratar de "uso correto do LD", deixando-nos entender que ele parte de uma visão para outra, substituindo uma verdade por uma outra.

Sobre esse "uso correto do LD" citado por Krisler, Jane demonstrou uma atitude diferenciada, destacando, para além da dicotomia uso certo e errado, o entendimento do papel que o docente pode desempenhar quando possui uma formação voltada para o ensino de língua como prática social, o que implica, dentre outros aspectos, o desenvolvimento da criticidade nas interações que surgem entre os diferentes agentes do processo de ensino-aprendizagem com os conteúdos dos materiais didáticos. Para ela, tratase menos de uso correto ou incorreto do LD, e mais de cautela e atenção; afinal, "o livro didático é uma fonte rica a ser explorada por professores e alunos, mas isso deve ser feito com um olhar crítico e atento" (Fonte: questionário respondido por Jane, p. 3).

Inspirada nas ideias de Jucá (2016) a respeito de sua experiência com formação de professores de língua inglesa de escola pública e produção de material didático, Jane destaca a ideia do professor também como recurso, além do livro didático, o que parece apontar para uma visão mais dinâmica acerca do papel do livro didático no ensino de inglês, reforçando o seu entendimento como indo além de uso certo e errado do LD. 


\section{Experiências de formação inicial de professores de inglês em contexto extensionista: discutindo a multimodalidade e os materiais didáticos \\ Ana Karina de Oliveira Nascimentos, Maria Amália Vargas Façanba}

Nesse sentido, Jane entende que apesar da riqueza do livro didático, “[...] o que está ali precisa ser problematizado" (Fonte: questionário respondido por Jane, p. 3). De maneira mais geral, ligada ao olhar mais crítico por parte dos docentes, ela destaca que uma questão a ser problematizada é o fato de que, apesar de ter havido avanços relativos à elaboração e à qualidade dos livros didáticos através do PNLD, "o livro é um produto comercial. Então, há muito do neoliberalismo nele" (Idem, Ibidem).

Essa relação entre as coleções do PNLD e interesses neoliberais surgiu do diálogo embasado, principalmente, na análise que Zacchi (2016) faz de uma coleção do referido programa, a qual aponta haver avanços na produção de materiais didáticos de língua inglesa apesar da presença ainda perceptível de elementos correspondentes a valores neoliberais, como é o caso da busca pelo sucesso individual, representado através do tema celebridades. Esses valores, entretanto, segundo ele, aparecem em uma relação ambígua com outros valores relativos a princípios e critérios de produção estabelecidos pelo programa nacional, tais como: a valorização da diversidade, representação positiva dos direitos das minorias (negros, indígenas, mulheres, etc.), respeito às diferenças culturais locais e globais, entre outros. Segundo o autor:

Embora a completa erradicação de tais ambiguidades seja pouco provável, a iniciativa do MEC com o PNLD parece ser um bom passo na direção da produção de materiais que 'incorporam valores outros além daqueles expressos pela indústria de materiais didáticos de línguas' (GRAY, 2012, p. 111 apud ZACCHI, 2016, p. 170).

Além de considerar análises críticas envolvendo, por exemplo, o neoliberalismo e sua relação com a língua inglesa, as discussões e análises sobre o livro/material didático aconteceram através de práticas envolvendo a multimodalidade. Para tal, levamos em conta as considerações destacadas pelas Orientações Curriculares para o Ensino Médio - OCEM (BRASIL, 2006) a respeito da formação crítica, inclusive dentro de um projeto de inclusão digital e social, quais sejam:

1) há outras formas de produção e circulação da informação e do conhecimento, diferentes das tradicionais aprendidas na escola; 2) a multimodalidade requer outras habilidades de leitura, interpretação e comunicação, diferentes das tradicionais ensinadas na escola; 3) a necessidade da capacidade crítica se fortalece não apenas como ferramenta de seleção daquilo que é útil e de interesse ao interlocutor, em meio à massa de informação à qual passou a ser exposto, mas também como ferramenta para a interação na sociedade, para a participação na produção da linguagem dessa sociedade e para a construção de sentidos dessa linguagem (BRASIL, 2006, p. 97-98). 
Ao falar da experiência com esse tema durante o projeto, Jane destacou desconhecer, até sua participação no módulo, a concepção de Kress (2003) sobre multimodalidade, e que estava sendo por nós adotada ao longo do curso:

As questões sobre multimodalidade podem ser pensadas em pelo menos três maneiras distintas e relacionadas. Primeiro, todos os textos são multimodais. Meu argumento é que nenhum texto pode existir em apenas um modo; portanto, todos os textos são multimodais embora uma modalidade dentre elas possa dominar. Segundo, há textos e objetos (do tipo semiótico) os quais existem predominantemente em um modo ou modos diferentes do (multi) modo da linguagem. E terceiro, há sistemas de comunicação e de representação os quais são reconhecidos na cultura por serem multimodais, embora, de fato, todos esses sistemas sejam multimodais ${ }^{8}$ (KRESS, 2003, p.187-188, grifos nossos).

Para Jane, a multimodalidade se manifestava apenas através da "união de dois ou mais textos monomodais, como textos que uniam imagem e escrita ou áudio e imagem" (Fonte: questionário respondido por Jane, p. 3). As práticas desenvolvidas durante o módulo, envolvendo diferentes materiais e textos despertaram nela a compreensão de que todo texto carrega significados possíveis, e que "vimos no módulo que é possível dar aula até com garrafas d'água" (Idem, Ibidem).

Aqui a graduanda se refere a uma das atividades realizadas no módulo, inspirada em exemplo que Kress (2003) utilizou para tratar do conceito de multimodalidade, compreendendo a leitura de garrafas d'água em uma simples ida ao supermercado. Para realização da atividade, utilizamos diferentes marcas e modelos de garrafas para estimular a leitura daqueles objetos entendendo-os como textos multimodais. Sob a perspectiva de Kress,

nós respondemos a elas [as garrafas] como textos multimodais, os quais são significativos em cada aspecto de sua multimodalidade: nós vemos os rótulos, e os tratamos, embora de maneira fugaz, como textos de linguagem e imagem; nós percebemos se as garrafas são de vidro ou plástico - com algumas garrafas enfatizando suas materialidades e outras as disfarçando; nós reparamos em suas cores: verde, ou azul, ou claras; e percebemos seus formatos [...] (KRESS, 2003, p. 188).

No módulo, exploramos esses elementos enfatizando que estamos sempre lendo e interpretando textos que se manifestam através de diferentes modos, além da escrita. Que fazemos escolhas o tempo todo e o quanto somos influenciados na tomada de decisões, que vão do simples ato de compra de uma garrafa de água a questões mais complexas.

\footnotetext{
8 Todas as traduções da língua inglesa feitas ao longo do texto são de responsabilidades das autoras.
} 
Além das garrafas, também trabalhamos a leitura de camisetas, na mesma perspectiva aplicada à análise das garrafas. Esses objetos serviram para ajudar na expansão das perspectivas dos participantes quanto à leitura de textos sob uma perspectiva sociocultural, a qual implica olhares mais críticos, atentos às intencionalidades de quem os produz e de como sou levada(a) a determinadas interpretações. Em seu relato sobre sua experiência no módulo, Krisler destacou que:

Aprendemos a mudar nossa forma de ler o mundo, não somente a forma de lermos textos escritos, mas de qualquer coisa, seja a leitura de uma garrafa de água, uma camisa, ou até uma música. Exercitamos a todo o momento o uso de várias lentes de leituras para um mesmo objeto, tentávamos explorar todos os sentidos que poderiam haver em cada texto (Fonte: questionário respondido por Krisler, p. 1, grifos nossos).

Nessa passagem, o graduando Krisler trata da ampliação do conceito de texto e de possibilidades de leituras enfatizada durante o módulo, o que coaduna-se com a visão sociocultural de novos letramentos, referindo-se à ideia de que a "[...] atribuição de sentidos vai muito além da palavra escrita para englobar propósitos diferentes para: comunicar; novas e diferentes mídias para construção de sentidos; e contextos e práticas sociais diversas em que os sentidos são construídos e compartilhados [...]” (NASCIMENTO; KNOBEL, 2017, p. 69). E é nesse contexto que se insere a justificativa de adotarmos ao longo do módulo o conceito de letramentos acrescido do prefixo novos, de forma a sinalizar a mudança paradigmática e ontológica de se entender os letramentos. No que se refere ao primeiro, trata-se da mudança de uma perspectiva psicolinguística a uma perspectiva sociocultural como um novo paradigma teórico e de investigação para os estudos de letramentos, ou seja, ao entendimento dos letramentos como uma prática social. No que se refere ao segundo, relaciona-se à diferenciação entre práticas de letramento convencionais e as mais atuais, principalmente mudanças no que concerne a formas póstipográficas, transformações midiáticas, econômicas, tecnológicas, etc. (LANKSHEAR; KNOBEL, 2011; ZACCHI; STELLA, 2014).

Entretanto, é possível perceber ainda, por meio do destaque trazido na citação da resposta de Krisler que, ainda que o graduando tenha ampliado seu entendimento em relação a textos e suas possibilidades de leitura, ainda há menção a uma suposta totalidade interpretativa que parece se referir a um entendimento exagerado do que seria a ideia de expansão interpretativa, a ser tratada na seção seguinte. 


\section{Professores em formação inicial expandindo perspectivas}

"Participar do projeto me fez (re) pensar e questionar muitas coisas. Certamente, agora não vou olhar para uma imagem da mesma maneira que fazia antes" (Fonte: questionário respondido por Jane, p. 4). Essa afirmação da bolsista também foi observada nas falas dos docentes participantes e do bolsista Krisler, o qual destacou que "a presença de uma imagem no livro pode nos dizer muito sobre o material [...]. A imagem no livro possui um sentido assim como um emoticon porta um sentido no Whats App" (Fonte: questionário respondido por Krisler, p. 1). Esse paralelo com os emoticons sinalizou para nós haver uma conexão entre as discussões sobre multimodalidade que fizemos ao longo do módulo e as práticas sociais comuns àquele discente e àquele grupo com o qual convivemos e construímos diferentes significados.

Outro ponto interessante para ser mencionado sobre a observação feita por Krisler a respeito de imagens e o $\mathrm{LD}$, é que, além de falar da presença delas nos materiais didáticos, ele também menciona a ausência delas, no sentido da falta de representatividade de variados grupos, segmentos, etc., como elemento importante nas análises e usos do material didático. Segundo ele, "a falta de alguma forma (visual) também pode representar algo a respeito do livro" (Fonte: questionário respondido por Krisler, p. 1). Vale ressaltar que esse olhar mais atento sobre os elementos multimodais, com destaque para os textos visuais, tanto para o que está nele exposto como para as ausências, está em sintonia com o que Ferraz (2012, p. 107) afirma sobre a necessidade de reflexão a respeito do poder de persuasão das imagens ocorrer também na escola, destacando que cabe discutirmos "o poder de persuasão das imagens não somente na propaganda, mas também na área educacional e nas práticas de leitura em sala de aula, mais especificamente”.

Assim o fizemos ao longo do módulo, trabalhando com textos visuais de diferentes fontes e gêneros, além dos encontrados nas coleções do PNLD analisadas (videoclipes, imagens de revistas, propagandas, camisetas, garrafas de água, grafites, etc.), na perspectiva do mesmo autor, no sentindo de que "acreditamos também que as imagens são persuasivas e apresentadas ao aluno-espectador por meio de um discurso que as naturaliza e coloca, muitas vezes, como o discurso que representa a realidade” (FERRAZ, 2012, p. 107). Nessa direção, destacamos a seguinte reflexão feita por Jane, em resposta a uma das perguntas presentes no questionário utilizado aqui em nossas reflexões: Qual sua opinião a respeito das 
imagens presentes nos livros didáticos de inglês discutidas durante o módulo? Ela ressalta que o trabalho com imagens foi bastante explorado no módulo, com destaque para a compreensão de que

as imagens carregam as intenções/ideias do autor e geralmente, visam convencer o leitor desse tipo de texto a elas. Ou seja, as imagens são produzidas por seres humanos, seres sociais, e por isso, elas carregam a ideologia do seu autor, que foi construída no convívio social. Então, muitas "verdades" propagadas socialmente aparecem nas imagens, como por exemplo padrões de beleza. Tudo isso reforça ainda mais a necessidade de problematizar as imagens e desconstruir essas verdades para reconstruir algo novo (Fonte: questionário respondido por Jane, p. 4, grifos nossos).

Um dos pontos bastante discutidos foi justamente essa necessidade apontada por ela de problematizarmos a ideia de leitura como o ato de "desvendar a verdade" contida no texto, a qual foi construída por um determinado autor/autora, em determinado contexto, sendo ele/ela responsável pela mensagem/ideia propagada. Nas práticas de novos letramentos pensadas para o módulo, buscamos estabelecer uma outra abordagem de leitura, trabalhando a relação com os textos sob a lente do letramento crítico, o qual, segundo Menezes de Souza (2011, p. 293, grifo nosso), pode ser entendido como: "ir além da aparência da verdade; fazer o aluno refletir sobre aquilo que ele pensa que é natural $e$ verdadeiro".

Essa relação de naturalidade e de uma verdade ligada à interpretação textual pode gerar, segundo o autor, leituras carregadas de preconceito, interpretações únicas. Buscando provocar diferentes interpretações, trabalhamos os diversos textos com base no letramento crítico, no sentido de incentivar os docentes do ensino básico e os discentes bolsistas a vivenciarem situações de leitura no sentido de: "levar o aluno a refletir sobre a história, sobre o contexto de seus saberes, seu senso comum. Levar o aluno a perceber que para alguém que vive em outro contexto, a verdade pode ser diferente" (MENEZES DE SOUZA, 2011, p. 293).

Refletimos, assim, sobre a responsabilidade do leitor pelas interpretações feitas, no sentido de expandir leituras cujo foco está "na verdade" que o texto carrega, a qual foi construída por seu autor/autora, em determinado contexto. Essa visão de leitura, a qual transfere para o autor do texto a responsabilidade pela verdade que ele quer transmitir faz parte, lembra Menezes de Souza (2011), de prática pautada na pedagogia crítica. Pedagogia essa de cunho marxista, cuja "preocupação principal é introduzir a justiça social, a igualdade, em contextos onde não havia igualdade ou justiça social. Neste contexto, ser ‘crítico' consiste em perceber a verdade por trás da ilusão” (MENEZES DE SOUZA, 


\section{Experiências de formação inicial de professores de inglês em contexto extensionista: discutindo a multimodalidade e os materiais didáticos \\ Ana Karina de Oliveira Nascimentos, Maria Amália Vargas Façanba}

2011, p. 290). O autor afirma que, no letramento crítico, há uma redefinição do que seja consciência crítica. Segundo ele:

Aqui, no letramento crítico, precisamos assumir a responsabilidade das nossas leituras e não culpar o autor do texto pela sua escritura; precisamos perceber que o significado de um texto é uma inter-relação entre a escrita e a leitura. Nós estamos nos conscientizando sobre como nós interpretamos o texto (Idem, 2011, p. 293).

Nesse sentido, buscamos problematizar o conceito de "verdade", no singular, de acordo com leitura embasada no letramento crítico, para a compreensão plural de que, ao invés de falarmos em verdade ou verdades, podemos pensar em termos de perspectivas, as quais são construídas e desconstruídas na interação entre texto, contexto, autor e leitores. Monte Mór (2011), entendendo a leitura como prática social, fala sobre o papel da escola em relação ao que ela denomina de "expansão de perspectivas", o que pode acontecer na relação que se estabelece no processo de produção de sentidos, sob a perspectiva do letramento crítico, por meio de práticas que contemplem e relacionem questões ligadas às dimensões que envolvem aspectos individuais, globais e comunitários. Ao falar em expansão de perspectivas, a autora destaca que:

[...] as características intrínsecas à linguagem e comunicação também o são à interpretação, considerando-se que há uma busca por um núcleo comum de sentidos que, de certa forma, garanta que as pessoas apreendam a comunicação de forma igual ou semelhante. Logo, por meio das pesquisas realizadas, avaliei que esse mesmo raciocínio se aplicaria à leitura e interpretação, ou à construção de sentidos. Em alusão ao habitus linguístico descrito por Bourdieu (Ibid.), concluo que as pessoas formam e seguem um habitus interpretativo, respondendo às expectativas das instituições que geram e regulam os sentidos. No entendimento de que esse processo se permeia por forças politicas, sociais e culturais dominantes, considero que o habitus interpretativo desenvolvido nos indivíduos opera segundo os valores dessas forças dominantes que, porém, podem não ser permanentes (MONTE MÓR, 2018, p. 4-5, no prelo, grifos nossos).

A autora busca em Luke e Freebody elementos para reforçar a ideia de que a escola pode contribuir com a formação de leitores capazes de compreender "representações textuais, valores, ideologias, discursos, que se posicionem, que tenham visões de mundo e que compreendam que a leitura está relacionada com a distribuição de conhecimento e de poder em uma sociedade" (MONTE MÓR, 2011, p. 317). Essa formação, a qual implica olhares atentos voltados para um processo de (des)construção de significados e de expansão de perspectivas foi percebida por Jane da seguinte forma: "Nós, professores, devemos passar por esse processo de desconstrução/reconstrução para termos condições 
de proporcionar isso aos alunos. E, nós devemos estar ainda mais atentos para não impormos nossas verdades aos estudantes" (Fonte: questionário respondido por Jane, p. 4). Nesse sentido, pautadas nas falas de Krisler e Jane, entendemos que os professores em formação inicial foram capazes de, ao término do módulo, problematizarem não apenas suas visões como discentes de língua inglesa, mas especialmente, como docentes (ainda que) em formação inicial acerca de suas próprias verdades no que concerne às questões de multimodalidade e dos diferenciados textos presentes no livro didático de língua inglesa.

\section{Um processo em construção... E uma tentativa de concluir...}

Ao refletirem sobre possíveis mudanças advindas das trocas ocorridas durante todo o processo envolvendo o módulo, do seu planejamento aos encontros presenciais e pelas redes sociais, Jane declarou: "o projeto me ajudou a (re) pensar os meus objetivos como professora de inglês e a ver cada vez mais claramente que a língua não é neutra" (Fonte: questionário respondido por Jane, p. 4). E continuou afirmando que "participar do projeto me fez (re) pensar e questionar muitas coisas. Certamente, agora não vou olhar para uma imagem da mesma maneira que fazia antes" (Idem, Ibidem). Ela também declarou que a experiência com o módulo despertou seu interesse em intensificar seu papel como pesquisadora, aprofundando seus conhecimentos a respeito dos temas tratados no módulo.

Para Krisler, "o módulo representou um marco em minha visão da relação existente entre o professor, os alunos e o material didático" (Fonte: questionário respondido por Krisler, p. 1), aí incluídas discussões a respeito da multimodalidade. E aponta para o grau de importância daquela vivência de extensão no seu processo formativo, com ênfase nos relatos de experiências de docentes da rede pública a respeito de situações vividas em sala de aula, as quais, segundo ele, são únicas e "não podem ser encontradas facilmente em livros" (Idem, Ibidem).

Conforme trazem os professores em formação inicial por meio de suas respostas a perguntas presentes em questionário final respondido após o término do módulo, suas participações na ação extensionista promoveram um repensar das práticas docentes, principalmente no que concerne às questões de multimodalidade e material didático de inglês, em especial o livro. Tal constatação, para além das falas dos próprios participantes também pode ser vivenciada, conforme pudemos perceber como observadoras e registrar 
em nossos diários de campo quando, por exemplo, ainda que sendo facultado aos graduandos a criação do artefato didático parte do projeto final, ainda assim Krisler fez questão de preparar e apresentar aos demais componentes do grupo.

Jane, por sua vez, quando consultada sobre o interesse em participar de um evento direcionado a discentes da UPB no qual pudesse tratar sobre algo vivido no módulo que chamou sua atenção, prontamente aceitou e apresentou uma discussão sobre o livro didático de língua inglesa, embasada nas leituras e vivências parte do módulo.

Esses relatos, juntamente com os demais problematizados ao longo deste artigo apontam para um protagonismo dos discentes no que concerne ao seu processo de formação, permeado por reflexões, muitas delas resultantes das experiências vividas durante o módulo da ação extensionista aqui problematizado. Por outro lado, os dados também parecem apontar para uma ambivalência presente no processo formativo, que entendemos como parte da complexidade envolvida no processo, demonstrada por meio do entendimento de totalidade interpretativa, da obviedade quanto ao papel de ser mais aprendiz do que compartilhador de conhecimento, conforme pontuou Krisler, bem como de que cabe ao professor desconstruir verdades para reconstruir algo novo, conforme pontuou Jane, ademais de ser função do professor problematizar de forma a promover a pluralidade e o compartilhamento de diversas verdades.

Assim, ao final desta análise por meio de narrativa descritivo-teórica, além de reconhecermos os interessantes realinhamentos na formação docente dos participantes, também achamos pertinente pontuar a existência de posicionamentos contraditórios, como forma de apontar a complexidade envolvida nos processos de formação docente.

\section{Agradecimentos}

Ao Conselho Nacional de Pesquisa - CNPq pela concessão de bolsa de doutorado no país e de doutorado sanduíche no país às autoras do presente texto, momento durante o qual ambas conduziram o módulo cujos resultados são analisados ao longo deste artigo. 


\section{Referências}

ANDRÉ, M. E. D. A. de. Etnografia da prática escolar. Campinas: Papirus, 1995.

BRASIL. Ministério da Educação. Secretaria de Educação Básica. Orientações curriculares para o ensino médio; volume 1 - Linguagens, códigos e suas tecnologias. Brasília: MEC, SEB, 2006.

FERRAZ, D. de M. Letramento visual: a leitura de imagem das aulas de inglês. Jundiaí: Paco Editorial, 2012.

GEE, J. P. Social linguistics and literacies: ideologies in discourses. 3 ed. Londres: Routledge, 2008.

JUCÁ, L. Ensinando inglês na escola regular: a escolha dos caminhos a seguir depende de onde se quer chegar. In: JESUS, D. M. de; CARBONIERE, D. (Org.). Práticas de multiletramentos e letramento crítico: outros sentidos para a sala de aula de línguas. Campinas: Pontes Editores, 2016, p. 99-120.

KRESS, G. Multimodality. In: COPE, B.; KALANTZIS, M. (Org.). Multiliteracies: literacy learning and the design of social futures. Nova Iorque: Routledge, 2003.

LANKSHEAR, C.; KNOBEL, M. Social learning, 'push' and 'pull', and building platforms for collaborative learning. In: New Literacies: everyday practices and social learning. Berkshire: Open University Press, 2011.

LEFFA, V. J.; IRALA, V. B. O ensino de outra(s) língua(s) na contemporaneidade: questões conceituais e metodológicas. In: (Org.). Uma espiadinha na sala de aula: ensinando línguas adicionais no Brasil. Pelotas: Educat, 2014, p. 21-48.

MATTOS, A. M. de A. Ensino de inglês como língua estrangeira na escola pública: letramentos, globalização e cidadania. Jundiaí: Paco Editorial, 2015.

MENEZES DE SOUZA, L. M. T. O professor de inglês e os letramentos no século XXI: métodos ou ética? In: JORDÃO, C. M.; MARTINEZ, J. Z.; HALU, R. C.

(Org.).Formação desformatada - práticas com professores de língua inglesa.

Coleção: Novas Perspectivas em Linguística Aplicada Vol. 15. Campinas: Pontes Editores, 2011.

MONTE MÓR, W. Critical literacies in the Brazilian university and in elementary/secondary schools: the dialectics between the global and the local. In: MACIEL, R. F.; ARAÚJO, V. A. (Org.) Formação de professores de línguas: ampliando perspectivas. Jundiaí: Paco Editorial, 2011.

Letramentos críticos e expansão de perspectivas: diálogo sobre práticas. In: JORDÃO, C. M.; MARTINEZ, J. Z.; MONTE MÓR, W. (Org.). Práticas de letramentos. 2018 (No Prelo).

NASCIMENTO, A. K. de O.; KNOBEL, M. What's to be learned? A review of sociocultural digital literacies research within pre-service teacher education. Nordic Journal of Digital Literacy v. 12, no 3, 2017, p. 67-88. 
SANTOS, D. Making sense of literacy: events mediated by the EFL textbook. In: MACIEL, Ruberval; ARAÚJO, Vanessa (Org.). Formação de professores de línguas: ampliando perspectivas. Jundiaí: Paco Editorial, 2011, p. 60-92.

SCHLATTER, M.; GARCEZ, P. de M. Línguas adicionais na escola: aprendizagens colaborativas em inglês. Porto Alegre: Edelbra, 2012.

ZACCHI, V. Neoliberalism, applied linguistics and the PNLD. Ilha do Desterro: A journal of English language, literature in English and cultural studies. Florianópolis, v. 69, n 1, Jan./Abr. 2016. Disponível em: <http://dx.doi.org/10.5007/2175-

8026.2016v69n1p161>. Acesso em: 3 set. 2016.

ZACCHI, V.; STELLA, P. Apresentação. In: (Org.). Novos letramentos, formação de professores e ensino de língua inglesa. Maceió: Edufal, 2014, p. 13-19. 


\begin{abstract}
Understanding the pre-service teaching education process as plural, this article investigates the experiences of English teachers, which occured in the community outreach project called Education of Teachers of English as an Additional Language, mainly in the course titled English Language Materials, developed according to the theories of new literacies (MENEZES DE SOUZA, 2011) and multimodality (KRESS, 2003). It is an exploratory analysis of ethnographic nature, classified as an ethnographic case study, which has the objective of problematizing how the participants, two pre-service teachers, volunteers in the project, understand multimodality and the role of teaching materials, mainly the schoolbook, in the teaching of English, considering their experiences in the project. The main results, which are discussed in this analysis through a theoretical-descriptive narrative, point to interesting realignments in the participants' teaching education process, though it is still possible to identify some contradictory positionings. We conclude bighlighting that the participation of pre-service teachers in the community outreach project promoted the (re) consideration of teacher practice, especially when it comes to multimodality and English textbooks.
\end{abstract}

Keywords: Pre-service teacher education. English teachers. Community outreach. Multimodality. Teaching material

Recebido em: 04/01/2018.

Aceito em: 03/06/2018. 